\title{
13. Controle efetivo e campo de controle: uma convergência trans-teórica entre a linguística cognitiva e a pragmática funcional no exemplo de verbos modais volitivos em português
}

Thomas Johnen

Stockholms universitet

\section{Introdução}

Analisando o uso do modo subjuntivo ${ }^{\mathrm{I}}$ em proposições factivas em português no âmbito da linguística cognitiva, Vesterinen (20I0) amplia análises anteriores que tinham postulado a relevância da categoria de controle epistêmico do conceitualizador para a questão da escolha do modo verbal no espanhol ( $c f$. p.ex. Maldonado I995). Vesterinen (20I0) propõe a categoria de controle efetivo sobre eventos para explicar o uso do subjuntivo em construções factivas como:

(I) Lamento que nessas manifestações não existam argumentos, mas apenas acusações $e$ insultos [http://wehavekaosinthegarden.blogspot.se/2009/ 03/prepotencias-e-mentiras.html] (Vesterinen 20I0: I69)

O subjuntivo conceitualiza em (I), segundo esta análise, que o conceitualizador não exerce controle efetivo sobre o evento descrito na proposição sub-ordinada.

Vemos nesta análise uma convergência trans-teórica interessante com a pragmática funcional ( $c f$. Ehlich 2007: 9-47; Redder 2008) que desenvolveu já nos anos 70 do século XX a categoria de campo de controle no âmbito da teoria de ação linguística desenvolvida por Rehbein $(\text { I } 977)^{2}$.

O objetivo deste artigo é exemplificar a relevância da categoria de campo de controle para os verbos modais ${ }^{3}$ volitivos $^{4}$ do português tanto na construção com infinitivo quanto na construção sintática com

Como citar este capítulo:

Johnen, Thomas, Controle efetivo e campo de controle: uma convergência trans-teórica entre a linguística cognitiva e a pragmática funcional no exemplo de verbos modais volitivos em português. In: Engwall, Gunnel \& Fant, Lars (eds.) Festival Romanistica. Contribuciones lingüisticas - Contributions linguistiques - Contributi linguistici - Contribuições linguísticas. Stockholm Studies in Romance Languages. Stockholm: Stockholm University Press. 20I 5, pp. 259-272. DOI: http://dx.doi.org/IO.I6993/bac.m. License: CC-BY 
uma proposição sub-ordinada introduzida pelo subjuntor ${ }^{5}$ que com co-referencialidade dos sujeitos do verbo modal e do verbo subordinado ${ }^{6}$.

\section{Linguística cognitiva e pragmática funcional}

De maneira simplificada é possível indicar como ponto de partida da linguística cognitiva a questão de como a língua conceitualiza em diferentes níveis de abstração a experiência humana ( $c$. p.ex. Langacker I999: I-43).

A pragmática funcional que é uma corrente linguística desenvolvida particularmente por Konrad Ehlich e Jochen Rehbein (cf. Ehlich 2007: 9) enfoca principalmente a finalidade da atividade verbal (sprachliches Handeln) e parte do pressuposto que a atividade verbal é em primeiro lugar, a interação entre falante e ouvinte (cf. Ehlich 2007: I3) categorias das quais a linguística cognitiva costuma fazer abstração7. A interação verbal é considerada na pragmática funcional uma das formas de interação entre agentes ${ }^{8}$. Daí surge a necessidade de desenvolver uma teoria de ação que englobe tanto ações verbais como não-verbais.

A teoria de ação desenvolvida por Rehbein (I977), no entanto, não objetiva fundamentar uma teoria da realidade, mas descrever em análises detalhadas fragmentos da realidade e sua complexidade, chegando a uma análise exemplar de padrões acionais relevantes para as funções que a atividade verbal pode ter ( $c f$. Rehbein I977: 5-8). O ponto de partida da pragmática funcional, portanto, não é a conceitualização da experiência humana, mas a realidade concreta que fornece as condições fundamentais para que se possa agir.

Tendo em vista estes dois pontos de partida diferentes, revela-se ainda mais interessante a convergência trans-teórica mencionada acima. Vesterinen (2010) chega a postular:

o conjunctivo assinala que o evento está fora do domínio do conceptualizador por este ter uma restringida possibilidade de influenciar o mesmo evento (Vesterinen 2010: I69).

Desta maneira, o autor atinge a interface entre conceitualização da realidade pela linguagem e a realidade acional, demonstrando de fato na sua abordagem uma certa convergência com a teoria acional da pragmática funcional, aproximando-se, contudo, do ponto de partida oposto: a partir da conceitualização e não da realidade acional. Vesterinen (20IO), além disso, não responde e tampouco se interessa pela questão do que significa ter a possibilidade de influenciar um evento e não 
apresenta nenhum elemento para o des-envolvimento de uma própria teoria de ação.

A teoria de ação rehbeiniana (Rehbein I977) analisa a complexidade da realidade acional como um fundamento para uma teoria linguística. Como a pragmática funcional é menos conhecida no mundo lusófono, convém apresentar a seguir os elementos fundamentais da teoria de ação desenvolvida no âmbito desta corrente linguística.

\section{As categorias do espaço acional na teoria de ação de Rehbein (1977)}

Rehbein (I977) parte do pressuposto que cada ação acontece em um espaço acional determinado (por exemplo, uma sala de aula). Cada espaço acional é determinado por certas categorias. Rehbein (I977) distingue entre categorias da dimensão subjetiva (como os mecanismos de percepção, de avaliação, do “crer” e de motivação dos agentes, bem como os seus conhecimentos e faculdades) e categorias de dimensão objetiva (como o campo acional, o espaço interacional, o campo de controle e o sistema das necessidades).

No contexto deste artigo, interessam antes de tudo duas categorias da dimensão objetiva do espaço acional: o campo acional e o campo de controle.

Por campo acional Rehbein (I977) entende o conjunto de atos dos quais um agente dispõe potencialmente em um dado momento e a ação escolhida. Por campo de controle o autor entende todos os elementos ao alcance imediato ou mediato do agente.

Partindo da análise de fragmentos da realidade relevantes para a escolha e a execução de uma determinada ação, Rehbein (1977) chega, portanto, a uma categoria que determina as condições objetivas de restrição de alternativas acionais num contexto acional determinado.

A vantagem desta abordagem é que fornece tanto um instrumentário de categorias relevantes para a análise de interações concretas quanto para a conceitualização da realidade pela linguagem.

Isso é evidenciado, por exemplo, pelos estudos de Brünner \& Redder (1983) sobre os verbos modais do alemão que analisam tanto a conceitualização das categorias acionais pelos verbos modais quanto as funções dos mesmos em ações verbais (como a OFERTA DE AJUDA) integradas em ações não-verbais concretas (como por exemplo COLOCAR UMA CORTINA). Nesta análise, Brünner \& Redder (I983) dividem os verbos modais em dois grupos: um de verbos como al. wollen 
'querer' que designam objetivos acionais e um outro como al. können 'poder' e al. müssen 'ter de' que designam e ponderam alternativas acionais.

\section{A categoria de campo de controle na semântica de verbos modais designativos de objetivos acionais}

$\mathrm{Na}$ recepção e aplicação das abordagens da pragmática funcional ( $c f$. Rehbein I977, Brünner \& Redder I983, Wunderlich I98I) aos verbos modais do português apresentada em Johnen (2003), mostramos que a categoria de campo de controle possui uma função semântica distintiva em relação aos verbos modais que designam um objetivo acional (verbos como gostar de, desejar, almejar, pretender, querer etc.) (cf. Johnen 2003: 250-350) e identifica assim, na periferia deste grupo de verbos modais, três verbos na construção com infinitivo (contar ${ }^{9}$, esperar e sonhar ${ }^{10}$ ) que marcam que a ação / o evento modalizado está fora do campo de controle do agente (cf. Johnen 2003: 344-347).

Esperar e sonhar + infinitivo são relacionados à fase de motivação no processo acional, bem como verbos como desejar e almejar + infinitivo. Isso significa que a semântica destes verbos tematiza que a ação designada no infinitivo é desejável por ter certas propriedades, sem considerar efeitos ou implicações negativas desta ação. Ainda não há nenhuma decisão de execução da ação. A realizabilidade da ação também não é tematizada. Desejar e almejar se distinguem apenas na intensidade da desiderabilidade da ação ( $c f$. Johnen 2003: 284).

Como foi dito anteriormente, esperar e sonhar + infinitivo, porém, marcam que a ação está fora do campo de controle do agente. A diferença entre os dois verbos é que sonhar + infinitivo marca que a ação está claramente fora do campo de controle, enquanto no caso de esperar + infinitivo, se trata de uma avaliação que, na última análise, o agente não controla a ação, mesmo se haja alguns elementos favoráveis como mostram (2)-(3):

(2) sonho em fazer o mestrado mais nao [sic] tenho condições finaceira [sic]. Atuo na Educação Infantil a mais de 20 anos. Como fazer para conseguir uma bolsa de estudo? ${ }^{\text {II }}$

(3) Fazer um [sic!] faculdade é legal, pois além de você ganhar experiência, também conhece pessoas legais, porém não é garantia de sucesso, mas é bem proveitoso. Estou cursando a minha segunda faculdade e espero fazer, Mestrado [sic!] e doutorado se Deus quiser ${ }^{12}$ 
Em (2) o autor não possui condições financeiras para realizar a ação, em (3) já está a caminho da realização, pois já tomou as primeiras medidas, mas o objetivo final é fora do seu campo de controle o que é enfatizado também pelo marcador se Deus quiser. Almejar e desejar não tematizam na sua semântica a questão do campo de controle.

Contar + infinitivo é relacionado à fase de execução e localizado no processo acional posterior à decisão de execução (bem como ir + infinitivo). Enquanto ir + infinitivo tematiza antes de tudo que a decisão da execução foi feita e que se trata de um objetivo normalmente no campo de controle do agente (cf. Johnen 2003: 306-319), contar + infinitivo tematiza em primeiro lugar que a ação que está para ser executada em última análise está fora do campo de controle do agente.

(4) De [sic! sc. se] tudo correr bem, conto em fazer uma breve visita. Até já! ${ }^{13}$

Estes exemplos mostram que a categoria de campo de controle é relevante para a semântica do sistema dos verbos modais do português.

Vesterinen (2010: I64-165) aventa a hipótese de que as construções de querer, desejar e esperar + infinitivo mostrem "um maior grau de responsabilidade e controlo sobre o evento descrito pelo $V_{2}$, ou seja, sobre o evento descrito pela forma infinitiva do verbo" (I65), identificando a co-referência do sujeito como responsável por isso. O autor não analisa, porém, as diferenças semânticas entre os três verbos discutidos. Compara apenas as construções com infinitivo com as construções sintáticas com uma proposição sub-ordinada introduzida pelo subjuntor que sem co-referência de sujeitos do verbo da proposição subordinada e do verbo matriz ( $c f$. Vesterinen 2010: I63-164). A categoria de campo de controle possui, contudo, uma importância especial em casos de co-referencialidade entre o verbo matriz e o verbo da proposição subordinada, conforme mostraremos no ponto a seguir em nossa análise de um fenômeno até hoje negligenciado na literatura.

\section{A categoria de campo de controle no caso de co-referencialidade do sujeito de verbo matriz (sendo um verbo modal que designa um objetivo acional) e do verbo subordinado ${ }^{14}$}

Nas línguas, como o português, que possuem tanto verbos modais na construção com infinitivo quanto em certos casos com proposições subordinadas introduzidas por um subjuntor (aqui: que), o caso da 
co-referencialidade do sujeito dos dois verbos é um caso especialmente interessante, porque são formas concorrentes.

Em regra geral usa-se no caso de co-referencialidade o infinitivo. Mas em certos casos também a construção com a proposição subordinada introduzida pelo subjuntor que é possível. Vale, porém, ressaltar que esta forma é extremamente marcada. No entanto, não se trata de uma variação que seja regida por uma regra variável, mas, antes de tudo, de uma variação que marca um traço semântico divergente: [ \pm no campo de controle do agente].

Isso significa que se a ação no verbo que depende do verbo modal estiver no campo de controle do agente há preferência pelo infinitivo. Para marcar que não é o caso, é possível usar a construção com a proposição subordinada introduzida por que. Vemos o exemplo seguinte:

(5) Quero comer um abacaxi.

(6) ???Quero que eu coma um abacaxi.

Uma ação como COMER normalmente não está fora do campo de controle de um agente humano ou animal. É possível que exista uma situação onde não haja alimentos ou outros impedimentos, mas a ação de COMER em si é uma ação habitualmente controlada por um agente humano ou animal. Assim, a opção pelo infinitivo parece obrigatória.

Os exemplos (7)-(I I) mostram, porém, que em certos contextos os usuários da língua optam também em caso de co-referencialidade pela proposição subordinada introduzida pelo subjuntor que:

(7) /gabriel says: January I, 20I 2 at I 7:29/ desejo paz a todos . quero que eu ganhe um celular . e tambem quero bastente [sic!] brinquedos ${ }^{15}$

(8) gugu eu quero que você realize esse sonho pra mim, eu quero conheser [sic!] os rebeldes da record 20II, eu quero que eu seja feliz, se voce puder me ajuda beijos gugu. rua sarutaia 767 bairro ze pereira / campo grande ${ }^{\mathrm{I}}$

(9) É isso... Beijo para vocês meninas e para os futuros leitores que eu pretendo que eu tenha! ${ }^{17}$

(Io) eu gostaria que eu pudesse bloquear as pessoas que eu não gosto de ficarem visitando meu orkut ${ }^{18}$

(II) Sou humana. Sou quase normal. Não ligo se gostarem de mim em partes. Mas desejo que eu me aceite por inteiro ${ }^{19}$ 
O que (7) a (I I) têm em comum é que se trata no caso do verbo da proposição subordinada sempre de ações ou eventos fora do controle do agente. No caso de ganhar e ser feliz é inerente à semântica, nos casos de ter, poder bloquear e aceitar-se é um efeito do contexto. Este fato é reforçado pela escolha da construção subordinada e pelo subjuntivo. Isso mostra uma prova de comutação exemplar de alguns dos exemplos abaixo:

(7) [...] desejo paz a todos . quero que eu ganhe um celular . e tambem quero bastente [sic!] brinquedos

(7’) desejo paz a todos . quero ganhar um celular . e tambem quero bastente [sic!] brinquedos

(8) gugu eu quero que você realize esse sonho pra mim, eu quero conheser [sic!] os rebeldes da record $20 \mathrm{I}$, eu quero que eu seja feliz, se voce puder me ajuda $[\ldots]$

(8') gugu eu quero que você realize esse sonho pra mim, eu quero conheser [sic!] os rebeldes da record 20I I, eu quero ser feliz, se voce puder me ajuda

Tanto em (7) e (8) quanto em (7') e (8') trata se de verbos ou colocações verbais (ganhar e ser feliz) que não atribuem ao sujeito um papel semântico de agente. No caso de querer + infinitivo, o verbo no infinitivo, porém, não determina o papel semântico do sujeito, mas se trata, antes de mais nada, de uma co-valência aditiva onde ambos os verbos mantêm sua valência semântica ( $c f$. Johnen 2005: 86-87). Desta maneira, já a valência semântica do verbo ganhar na acepção de 'receber como presente' bem como a da colocação ser feliz, marcam que não se trata de algo sob o controle do agente. A escolha da construção subordinada com o subjuntivo reforça este fator. Pela discrepância entre o objetivo e a falta de controle, intensifica-se desta maneira o grau da desiderabilidade do objetivo.

Bloquear em (Io) atribui ao sujeito o papel semântico de agente. Mas neste exemplo bloquear é ainda modalizado por poder. Bloquear torna se então um objetivo desejável, mas ainda não elegível.

(IO) eu gostaria que eu pudesse bloquear as pessoas que eu não gosto de ficarem visitando meu orkut

(IO') eu gostaria de poder bloquear as pessoas que eu não gosto de ficarem visitando meu orkut

A comparação entre (IO) e ( IO') mostra que a construção subordinada acentua ainda mais a inelegibilidade da ação bloquear. Para isso deve contribuir também o subjuntor $q u e^{20}$. 
É interessante observar que se modalizarmos comer com conseguir em (6) a aceitabilidade aumenta:

(II) Quero que eu consiga comer um abacaxi.

Também aqui a modalização torna a ação no verbo subordinado como algo inelegível no contexto. Isso contribui para a aceitabilidade da construção.

Em geral, é possível constatar que estes exemplos convergem com a análise apresentada por Augusto Soares da Silva (neste volume, Quadro I) de que a distância conceitual, a independência do evento subordinado, a objetividade do evento e a subjetividade do eixo subjetivo são de um grau maior na construção com a proposição subordinada do que na construção com infinitivo, e também que a atualização (o grounding) é total e, por último, que há uma instância de processo tipo escaneamento sequencial (em vez de sumário como no caso da construção com o infinitivo). Além disso, ressalta o autor (como implicação da maior distância conceitual) um grau de controle menor do sujeito relativamente ao evento subordinado.

Como o subjuntivo é obrigatório nestas construções é difícil (senão impossível) distinguir entre a contribuição semântica do subjuntivo e da construção sintática. O que aparenta é que se reforçam mutuamente.

Como foi mencionado anteriormente, as formas com a proposição subordinada são altamente marcadas. Consciente da limitação do método, analisamos, como uma primeira orientação a frequência das construções em (6)-(I 2) com as construções com infinitivo na base de dados de Google (www.google.se) ${ }^{21}$. Indicamos a frequência no dia da consulta (ro de maio de 20I3) e a porcentagem de cada construção (relativo à soma dos números de ocorrências da construção com infinitivo e com proposição subordinada). O resultado é mostrado no Quadro I.

As diferenças consideráveis quanto às preferências da construção com infinitivo em comparação com a proposição subordinada, são um indício para a importância da inter-relação entre a semântica do verbo subordinado e a escolha da construção. Comer e ter são verbos que não marcam, pela própria semântica, uma falta de controle do agente. Nestes verbos quase $100 \%$ das ocorrências são com o infinitivo. No caso de ganhar e ser feliz, a semântica do verbo subordinado marca o evento (ganhar) ou um estado (ser feliz) que não estão plenamente sob o controle do agente. Este somente pode escolher ações com o objetivo de alcançar o estado ou respectivamente contribuir para que o evento aconteça. Mesmo sendo pequena a porcentagem com a proposição subordinada, a frequência 
relativa é mais de mil vezes superior ao caso da construção com comer como verbo subordinado.

Quadro 1. Frequência das construções com infinitivo e com proposição sub-ordinada dos exemplos (6)-(I2) na base de dados Google

\begin{tabular}{|c|c|c|c|}
\hline $\begin{array}{l}\text { Verbo modal + } \\
\text { infinitivo }\end{array}$ & $\begin{array}{l}\text { Número de } \\
\text { ocorrências / } \\
\text { porcentagem }\end{array}$ & $\begin{array}{l}\text { Verbo modal + } \\
\text { que + subjuntivo }\end{array}$ & $\begin{array}{l}\text { Número de } \\
\text { ocorrências / } \\
\text { porcentagem }\end{array}$ \\
\hline quero comer & $\begin{array}{l}407.000 \\
99,99 \%\end{array}$ & $\begin{array}{l}\text { quero que eu } \\
\text { coma }\end{array}$ & $\begin{array}{r}5 \\
<0, \text { OI \% }\end{array}$ \\
\hline pretendo ter & $\begin{array}{l}\text { I } 48.000 \\
99,99 \%\end{array}$ & $\begin{array}{l}\text { pretendo que } \\
\text { eu tenha }\end{array}$ & $\begin{array}{r}3 \\
<0, \text { OI \% }\end{array}$ \\
\hline quero ser feliz & $\begin{array}{r}\text { I.222.000 } \\
98,83 \%\end{array}$ & $\begin{array}{l}\text { quero que eu } \\
\text { seja feliz }\end{array}$ & $\begin{array}{l}\mathrm{I} 4.400 \\
\mathrm{I}, \mathrm{I} 7 \%\end{array}$ \\
\hline eu gostaria de poder & $\begin{array}{r}\text { I. } 480.000 \\
85,85 \%\end{array}$ & $\begin{array}{l}\text { eu gostaria } \\
\text { que eu pudesse }\end{array}$ & $\begin{array}{l}244.000 \\
\text { I } 4, \text { I } 5 \%\end{array}$ \\
\hline quero conseguir & $\begin{array}{r}60.000 \\
68,26 \%\end{array}$ & $\begin{array}{l}\text { quero que eu } \\
\text { consiga }\end{array}$ & $\begin{array}{r}27.900 \\
31,74 \%\end{array}$ \\
\hline quero ganhar & $\begin{array}{l}931.000 \\
99,74 \%\end{array}$ & $\begin{array}{l}\text { quero que eu } \\
\text { ganhe }\end{array}$ & $\begin{array}{r}2460 \\
0,26 \%\end{array}$ \\
\hline
\end{tabular}

No caso dos verbos poder e conseguir como verbos subordinados, a porcentagem significativamente mais alta de construções com proposição sub-ordinada em comparação com os outros casos analisados, pode ser explicada pelo fato de estes dois verbos tematizarem a existência de uma alternativa acional: poder a existência em geral ( $c f$. Johnen 2003: 359-368), conseguir é um verbo operativo-fatitivo no sentido de Lyons (I988: 49I) e tematiza o resultado de um processo ( $c f$. Johnen 2003: 373-377). A existência de uma possibilidade acional bem como o resultado de uma ação, no entanto, são muitas vezes fora do espaço controlado pelo agente. A explicitação da possibilidade inerente, por exemplo, acontece, como mostra Kratzer (I98I), apenas em contextos nos quais não é esperada.

\section{Considerações finais}

Mostramos a convergência entre as categorias da pragmática funcional e da linguística cognitiva relativo às categorias de campo de controle e 
controle efetivo que existe apesar de todas as diferenças entre as duas abordagens linguísticas. A nosso ver, isso é um sinal da adequação das descrições. Há, no entanto também diferenças: enquanto a linguística cognitiva se auto-restringe à questão da conceitualização, a pragmática funcional apresenta ferramentas analíticas tanto para analisar a conceitualização de formas linguísticas quanto a própria realidade acional. A pragmática funcional fornece o instrumentário analítico para analisar interações concretas (inclusive a inter-relação entre a conceitualização e fatores situacionais), algo que não está no foco da linguística cognitiva.

\section{Notas}

I. Seguimos neste artigo com a denominação subjuntivo a nomenclatura gramatical brasileira. Em Portugal costuma-se usar a denominação de conjunctivo. Ambos os termos são sinônimos.

2. Cumpre mencionar que também Pottier (200I: I79-I80) introduz uma categoria 'controle sobre o evento' e ressalta a relação com a volição.

3. Convém alertar que não consideramos verbo modal como uma categoria sintática, mas semântica. Nisso divergimos da definição de verbo modal em Silva (neste volume) que os considera (como muitos outros autores - $c f$. Johnen 2003: 64) como verbos de elevação. Diverge também da definição em Meisnitzer (2012: 337) que restringe os verbos modais ao grupo que permite tanto uma leitura epistêmica quanto uma leitura deôntica. Como mostramos em Johnen (2006), a origem desta categoria gramatical é semântica (cf. também Steffler 20I2b) e argumentamos que a primazia da semântica possui a vantagem de poder considerar um paradigma semântico na sua integralidade que, em última análise, representa formas com graus de gramaticalização diferentes ( $c f$. Johnen 2000) (em vez de classificar verbos semanticamente próximos em categorias distintas; $c f$. também Steffler 20 r2a). No âmbito de uma análise acional dos verbos modais, chegamos em Johnen (2003) numa divisão classificatória em verbos modais acionais, epistêmicos e avaliativos. Os verbos modais volitivos pertencem ao grupo dos verbos modais acionais e formam o sub-grupo dos verbos modais que designam um objetivo acional. Mesmo tendo analisado em Johnen (2003) apenas verbos modais na construção com o infinitivo, propusemos uma tipologia sintática diferenciando as variantes sintáticas existentes, distinguindo entre verbos modais principais (com complemento nominal ou tendo como complemento uma proposição subordinada) e verbos modais secundários com infinitivo ( $c f$. Johnen 2003: 74-75). Argumentamos que cada uma destas construções precisa ser analisada separadamente por causa da inter-relação entre sintaxe e semântica. 
4. Os verbos modais volitivos são verbos que designam um objetivo acional como almejar, desejar, pretender, querer, ir. Para alguns destes verbos existe a variante sintática como verbo modal principal com uma proposição subordinada como complemento.

5. Em vez do termo da gramática tradicional pouco feliz de conjunção subordinativa, preferimos o termo subjuntor por designar de maneira mais adequada a relação de subordinação (veja também Engel et al. I993: 880-88I).

6. Para uma análise de exemplos sem co-referencialidade veja-se Vesterinen (2010: I63-I65).

7. É interessante observar a ausência de falante, ouvinte e interação, por exemplo, no índice de Langacker ( I999: 4 I9-427). Na sua introdução à linguística cognitiva, Evans \& Green (2006: 9-II) porém, consideram a função interacional da linguagem. O espaço, no entanto, que as autoras concedem a esta função da linguagem é bastante restrito: três páginas de 782 .

8. A divergência quanto ao ponto de partida mostra-se também na terminologia usada. Enquanto a linguística cognitiva usa o termo conceitualizador, a pragmática funcional usa agente. Mesmo havendo uma intersecção referencial entre os dois termos, não podem ser considerados sinônimos. Como estão no foco do presente trabalho as categorias de controle efetivo e de campo de controle, não podemos aprofundar aqui a questão terminológica referente a conceitualizador e agente, pois exigiria uma análise temática mais ampla. A seguir usamos ambos os termos, conceitualizador e agente, conforme à abordagem teórica a qual fazemos referência.

9. Existem as seguintes variantes sintáticas: contar + infinitivo, contar em + infinitivo, contar com + infinitivo (cf. Johnen 2003: 344-345).

IO. Existem as seguintes variantes sintáticas: sonhar + infinitivo, sonhar em + infinitivo e sonhar com + infinitivo (cf. Johnen 2003: 346-347).

I I. http://www.educacaoadistancia.blog.br/professores-terao-bolsas-para-cursos-de-mestrado-profissional-a-distancia/ (ultimo acesso em 23 de maio de 20I2).

I 2. http://br.answers.yahoo.com/question/index?qid=20I 205 I 8 I 70907 AA2 HrQZ (último acesso em 3 I de janeiro de 2013 ).

I3. http://interculturacidade.wordpress.com/2012/02/06/noite-tematica-indianaI 2-fevereiro-I830/ (ultimo acesso em 23 de maio de 2012).

I4. A análise a seguir baseia-se em um capítulo não publicado que foi originalmente elaborado em I 996 como parte da tese de doutorado (Johnen 2003), mas que durante o processo de escrita foi excluído pela necessidade de uma focalização temática nos verbos modais na construção com o infinitivo. Ampliamos, 
porém, para este estudo a base empírica utilizando ferramentas (como a pesquisa na base de dados de Google) que ainda não existiam na época.

I 5 .http://www.recreio.com.br/blogs/blog/o-que-eu-quero-em-2o I 2/\#commentI 525 I I (último acesso em 23 de maio de 20I2).

I 6. http://guiadicas.net/quero-participar-do-quadro-sonhar-mais-um-sonho/ (último acesso em 23 de maio de 20I2).

I 7. https://www.fanfiction.com.br/historia/I90864/Perfection_Tricks/capitulo/4 (último acesso em 23 de maio de 20I2).

I 8. http://productforums.google.com/forum/\#!category-topic/orkut-pt/suges$\mathrm{t}_{\%} \mathrm{C}_{3} \% \mathrm{~B}_{5}$ es-para-o-orkut/RnLtjamC $36 \mathrm{c}$ (último acesso em 23 de maio de 2OI2).

I9. http://pensador.uol.com.br/frase/MzY4MjAw/ (último acesso em 23 de maio de 20I2).

20. Para a uma análise mais detalhada das funções de conectores do tipo do subjuntor que veja Rehbein (2003).

2 I. Um problema é que o mesmo texto pode ser contado várias vezes. Por essa razão excluímos, por exemplo, da nossa pesquisa de frequência a construção “desejo que eu me aceite". Pois houve no dia de consulta I48.00o ocorrências que citam a mesma frase do mesmo texto.

\section{Referências}

Brünner, Gisela \& Angelika Redder. 1983. Studien zur Verwendung der Modalverben mit einem Beitrag von Dieter Wunderlich. Tübingen: Narr (Studien zur deutschen Grammatik; I9).

Ehlich, Konrad. 2007. Sprache und sprachliches Handeln, vol. I.: Pragmatik und Sprachtheorie. Berlin: de Gruyter.

Engel, Ulrich et al. I993. Kontrastive Grammatik deutsch-rumänisch. Heidelberg: Groos.

Evans, Vyvyan \& Melanie Green. 2006. Cognitive linguistics. An introduction. Edingburgh: Edingburgh University Press.

Johnen, Thomas. 2000. "Quem pode, pode, quem não pode se sacode: alcances e inconvenientes da pesquisa lingüística sobre os verbos modais portugueses". In: Gärtner, Eberhard, Christine Hundt \& Axel Schönberger (eds.). Estudos de gramática portuguesa (III). Frankfurt am Main: TFM. IO5-I 44 .

Johnen, Thomas. 2003. Die Modalverben des Portugiesischen (PB und 
PE). Semantik und Pragmatik in der Verortung einer kommunikativen Grammatik. Hamburg: Kovač (Philologia; 60).

Johnen, Thomas. 2005. "Observações sobre a valência semântica no Dicionário gramatical de verbos do português contemporâneo do Brasil". Lusorama, 6I-62. 76-95.

Johnen, Thomas. 2006. "Zur Herausbildung der Kategorie Modalverb in der Grammatikographie des Deutschen (und des Portugiesischen)". Pandaemonium Germanicum, Iо. 283-337, disponível online sob: http:// www.fflch.usp.br/dlm/alemao/pandaemoniumgermanicum/site/images/pdf/ ed2006/Zur_Herausbildung.pdf (09/05/2013).

Kratzer, Angelika. I98I. "The notional category of modality“. In: Eikmeyer, Hans-Jürgen \& Hannes Rieser (eds.). Words, Worlds, and Contexts: New Approaches in Word Semantics. Berlin / New York: de Guyter. 38-74.

Langacker, Ronald W. I999. Grammar and conceptualization. Berlin / New York: Mouton de Gruyter (Cognitive Linguistic Research; I4).

Lyons, John. I988. Semantics, vol. 2. 6a. ed. Cambridge: Cambride University Press.

Maldonado, Ricardo. 1995. "Middle-subjunctive links". In: Hamispour, Peggy, Ricardo Maldonando \& Margaret van Naerssen (eds.). Studies in language learning and Spanish linguistics in honor of Tracy D. Terrell. New York: McGraw-Hill. 399-4I 8.

Meisnitzer, Benjamin. 20I2. "Modality in Romance languages: Modal verbs and modal particles". In: Abraham, Werner \& Elisabeth Leiss (eds.). Modality and Theory of Mind across Languages. Berlin / New York: de Gruyter. 335-360.

Pottier, Bernard. 200 I. Représentations mentales et catégorisations linguistiques. Louvain/ Paris: Peeters (Bibliothèque de l'information grammaticale; 47).

Redder, Angelika. 2008. "Functional Pragmatics" . In: Antos, Gerd \& Eija Ventola (eds.): Handbook of interpersonal communication. Berlin / New York: de Gruyter. I33-I38.

Rehbein, Jochen. 1977. Komplexes Handeln. Elemente $z u$ einer Handlungstheorie der Sprache. Stuttgart: Metzler.

Rehbein, Jochen. 2003. "Matrix-Konstruktionen in Diskurs und Text". Zeitschrift für Interkulturellen Fremdsprachenunterricht, 8:2/3. 252-276.

Silva, Augusto Soares da. Neste volume. Subjetivação, objetificação e (des)gra-maticalização nas construções completivas infinitivas em português, em comparação com outras línguas românicas. 
Steffler Adriano. 20 I 2a. "Considerações acerca das relações entre modalidade e frases acionais”. In: Martha, Alice Áurea Penteado et al. (eds.). $2^{\circ}$ CIELLI Colóquio Internacional de Estudos Linguísticos e Literários. $5^{\circ}$ CELLI Colóquio de Estudos Linguísticos e Literários [recurso eletrônico]. Maringá: UEM-PLE, disponível sob: http://anais2or 2.cielli.com.br/pdf_trabalhos/957_arq_I.pdf (09/05/2013).

Steffler, Adriano. 20I 2b. "Uma analise diacrônica da categoria verbo modal em língua portuguesa”. In: Martha, Alice Áurea Penteado et al. (eds.). $2{ }^{\circ}$ CIELLI - Colóquio Internacional de Estudos Linguísticos e Literários. $5^{\circ}$ CELLI - Colóquio de Estudos Linguísticos e Literários [recurso eletrônico]. Maringá: UEM-PLE, disponível sob: http://anais2or 2.cielli. com.br/pdf_trabalhos/957_arq_2.pdf (09/05/20I3).

Vesterinen, Rainer. 2010. "Uma aproximação cognitiva ao modo conjuntivo". Revista Portuguesa de Humanidades. Estudos Lingüísticos, I4:I. I 5 I-I74.

Wunderlich, Dieter. I98I. "Modalverben in Diskurs und System". In: Rosengren, Inger (ed.). Sprache und Pragmatik. Lunder Symposium 1980. Lund: Gleerup (Lunder germanistische Forschungen; 50). I I-53. 


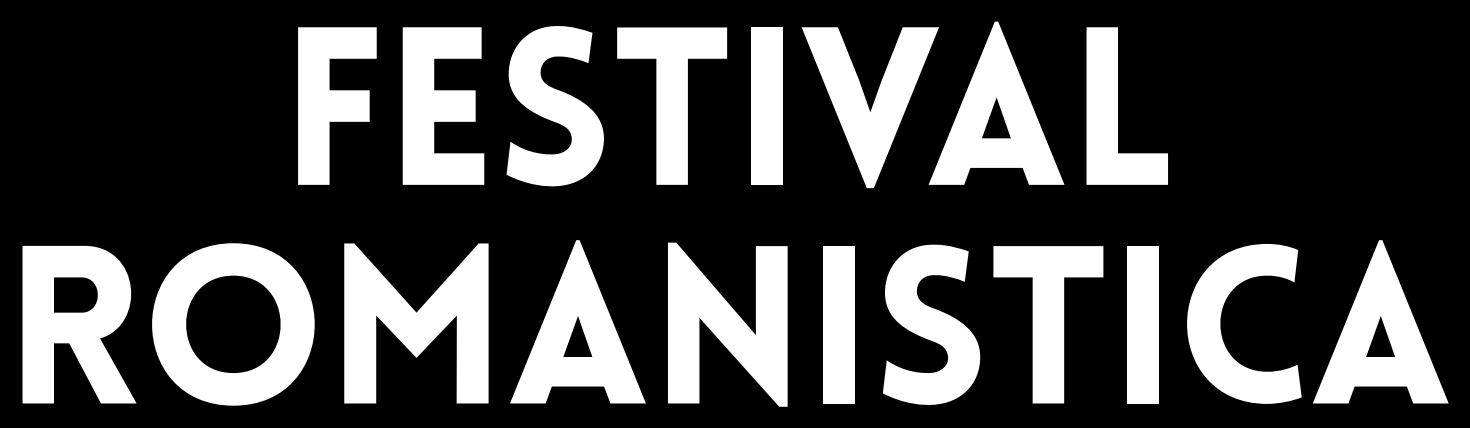

EDS: GUNNEL ENGWALL \& LARS FANT

CONTRIBUCIONES LINGÜISTICAS - CONTRIBUTIONS LINGUISTIQUES - CONTRIBUTI LINGUISTICI CONTRIBUIÇŌES LINGUÍSTICAS

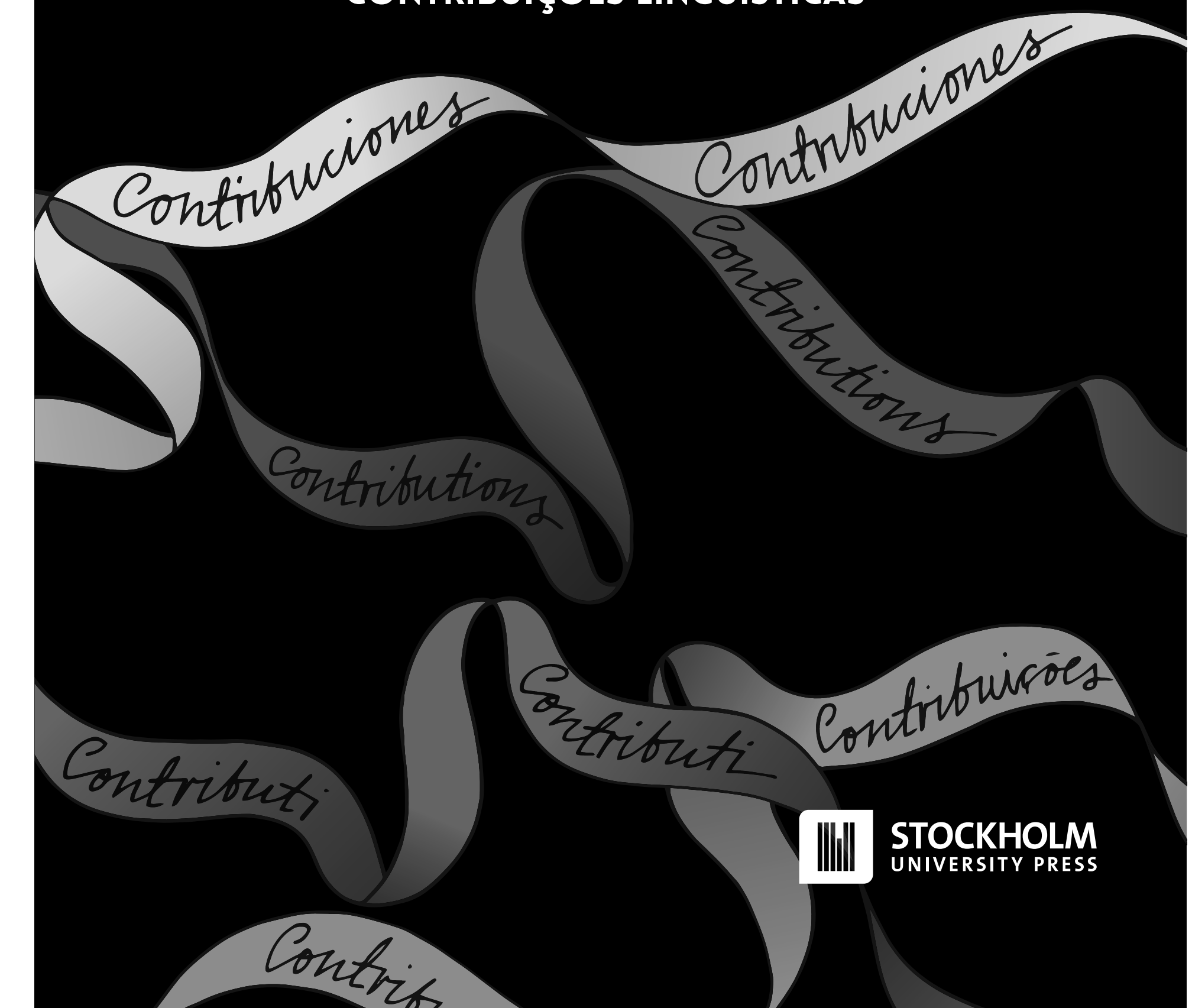




\section{Festival Romanistica}

Contribuciones lingüisticas - Contributions

linguistiques - Contributi linguistici - Contribuições

linguísticas

Gunnel Engwall \& Lars Fant (eds.) 
Published by

Stockholm University Press

Stockholm University

SE-I06 9i Stockholm, Sweden

www.stockholmuniversitypress.se

Text (C) The authors 20I 5

License CC-BY

Supporting Agency (funding): Department of Romance and Classical Studies, Stockholm University

First published 20I 5

Cover illustration by Liselotte Watkins Falk

Cover designed by Karl Edqvist, SUP

Stockholm Studies in Romance Languages (Online): ISSN 2002-0724

ISBN (Hardback): 978-9I-7635-OI I-9

ISBN (EPUB): 978-9I-7635-009-6

ISBN (Kindle): 978-9I-7635-010-2

ISBN (PDF): 978-9I-7635-008-9

DOI: http://dx.doi.org/I0.I6993/bac

This work is licensed under the Creative Commons Attribution 3.० Unported License. To view a copy of this license, visit http://creativecommons.org/licenses/by/3.o/ or send a letter to Creative Commons, 444 Castro Street, Suite 900, Mountain View, California, 9404I, USA. This license allows the downloading and sharing of the work, providing author attribution is clearly stated. The work cannot be changed in any way and cannot be used for commercial purposes.

Suggested citation:

Engwall, G. and Fant, L. (eds.) 20I 5 . Festival Romanistica. Contribuciones lingüisticas Contributions linguistiques - Contributi linguistici - Contribuições linguísticas.

Stockholm: Stockholm University Press. DOI: http://dx.doi.org/Io.I6993/bac

To read the free, open access version of this book online, visit http:// dx.doi.org/Io.I6993/bac or scan this QR code with your mobile device. 


\section{Stockholm Studies in Romance Languages}

Stockholm Studies in Romance Languages (SSIRL) is a peer-reviewed series of monographs and edited volumes published by Stockholm University Press. SSIRL strives to provide a broad forum for research on Romance Languages of all periods, including both linguistics and literature. In terms of subjects and methods, the orientation is wide: language structure, variation and meaning, spoken and written genres as well as literary scholarship in a broad sense. It is the ambition of SSIRL to place equally high demands on the academic quality of the manuscripts it accepts as those applied by refereed international journals and academic publishers of a similar orientation.

\section{Editorial Board}

Jean-Paul Dufiet, Professore associato, Lettere e Filosofia, Università degli Studi di Trento

Lars Fant, Professor, Romanska och klassiska inst., Stockholms universitet

Dominique Maingueneau, Professeur, UFR de Langue française, Université Paris IV

Cecilia Schwartz, Docent, Romanska och klassiska inst., Stockholms universitet

Françoise Sullet-Nylander, Professor, Romanska och klassiska inst., Stockholms universitet

Thomas Johnen, Professor, Fakultät SPR, Westsächsische Hochschule Zwickau

\section{Titles in the series}

I. Engwall, G. and Fant, L. (eds.) 2015. Festival Romanistica. Contribuciones lingüisticas - Contributions linguistiques - Contributi linguistici-Contribuições linguísticas. Stockholm: Stockholm University Press. DOI: http://dx.doi.org/Io.I6993/bac 


\section{Contenidos -Table des matières - Indice - Îndice}

Prefacio viii

Préface $x i$

Prefazione xiv

Prefácio xvii

\section{Plenarias - Plénières - Plenarie - Plenárias 1}

1 De la linguistique de la langue à la linguistique du discours, et retour 3

Patrick Charaudeau

2 Variazione sincronica e mutamento diacronico: il caso di alcuni connettori dell'italiano 13

Anna Giacalone Ramat

3 De nuevo sobre los signos adverbiales de modalidad epistémica que refuerzan la aserción en español actual: propiedades sintácticas y semánticas, y comportamiento discursivo 37 María Antonia Martín Zorraquino

4 Subjetificação, objetificação e (des)gramaticalização nas construções completivas infinitivas em português, em comparação com outras línguas românicas 64 Augusto Soares da Silva

5 Les constructions verbales en co(n)texte et en contraste : le cas du verbe observer 92 Dominique Willems

Comunicaciones - Communications - Comunicazioni Comunicações 111

6 Las metáforas espacio-temporales y la percepción del tiempo: un estudio comparativo sobre el español y el sueco 113

Emanuel Bylund \& Linn Andersson Konke 
7 Sim. Ahã. É. Sei. Aquisição das respostas curtas verbais afirmativas por bilíngues simultâneos sueco-brasileiros 131 Mary-Anne Eliasson

8 Un cas de proverbalisation en diachronie 160 Olof Eriksson

9 Atracción mutua: Estudio sobre los maximadores enteramente, completamente, totalmente y absolutamente en combinación con adjetivos y participios 175

Johan Falk

10 El uso de entonces e igual en hablantes nativos y no nativos de español chileno 198

Lars Fant

11 Verbe de manière de déplacement + direction dans une perspective de traduction suédois-français 219 Maria Fohlin

12 Los apéndices conversacionales en la argumentación: el caso de ¿cachái? 239

Johan Gille

13 Controle efetivo e campo de controle: uma convergência transteórica entre a linguística cognitiva e a pragmática funcional no exemplo de verbos modais volitivos em português 259 Thomas Johnen

14 Sur le rôle du nom commun dans le choix entre les appositions des trois types "le président Obama ", "Obama, le président " et " le président, Obama " en français et en suédois 273

Karin Lindqvist

15 L'ethos de crédibilité chez les candidats à la présidence :

l'exemple du pronom je présidentiel dans le débat

Hollande-Sarkozy 2012291

Malin Roitman

16 L'impact du contexte sur l'interprétation des composés. Le cas des composés NN en suédois et des constructions correspondantes en français 317

Maria Rosenberg

17 El pluscuamperfecto en las lenguas románicas 334 Ingmar Söhrman 
18 Metafore monetarie nella narrativa italiana del tardo Ottocento 346

Igor Tchehoff

19 Soggettività e oggettività negli articoli a carattere informativo di tre giornali italiani 360

Maria Tell 